\title{
Effect of Lowering the Reading Level of a Health Education Pamphlet on Increasing Comprehension by ESL Adults
}

\author{
James H. Bell \\ Reta E. Johnson
}

Does lowering the reading level of a health education pamphlet actually increase the comprehension by adult readers for whom English is a second language? We lowered the reading level of a general pharmacy education handout by changing vocabulary, sentence structure, and organization; by highlighting the main idea of each point; and by writing an introduction designed to catch attention and focus reading. Low-intermediate and advanced English as a Second Language (ESL) college students read either the unaltered (24 students) or altered (25 students) version of the pamphlet, which were estimated to be at the grade
12 and grade 7 level respectively according to the Flesch-Kincaid readability formula. Subjects then answered a free written test and a short-answer test. There was no statistically significant difference in the reading comprehension scores of the two groups on the free written test $(p=0.14)$ or on the short-answer test $(p=0.59)$. Health educators and ESL professionals should be wary of using readability formulas to estimate the suitability of materials for ESL readers, and of assuming that lowering the reading level of materials means increasing comprehension even when some changes beyond the lexical and syntactical are made.

One of the most important kinds of materials that English as a Second Language adults encounter is general health education material. Not understanding can be dangerous; misunderstanding can be just as bad. Health educators are becoming aware that much material is too difficult for many L2 readers. Often health professionals turn to ESL professionals for help with "lowering the readability level" of materials. The level is typically calculated with the assumption that lowering the readability level will increase comprehension. This assumption is not as common-sensical as it might first appear. We tested it in an experiment involving adult ESL students at an urban, Canadian college.

\section{REVIEW OF THE LITERATURE}

This study stems from concerns about, and research on, readability in health education and in English as a Second Language. 


\section{Readability and Health Education}

Health education materials are often too difficult for many readers to comprehend. By comparing the readability levels of materials analyzed by readability formulas with the estimated average reading level of adults (grades 8-9), it becomes clear that "much patient education material is potentially incomprehensible to a large portion of the adult population" (Vivian \& Robertson, 1980). Spadero (1983) found that of the 55 health brochures reviewed, only $14(25.5 \%)$ were written at or below the grade nine level. LaPierre and Mallet (1987) found the average reading level of 190 Canadian and American health education pamphlets to be grade $11.8 \pm 1.7$.

Rather than estimating the average adult reading level to be grade $8-9$, some studies actually measure the reading level of the target audiences for their health education materials. Doak and Doak found that the mean reading level of their subjects was approximately grade 7 as estimated by the Wide Range Achievement Test, but that the mean reading level of 100 samples of patient education material was approximately grade 10 (Doak, Doak, \& Root, 1985). Davis, Crouch, Wills, Miller, and Abdehou (1990) found that most health education materials they examined "required average reading comprehension grade levels of 11 th to 14 th" grade (p. 535), while the 151 patients averaged 6th grade 5th month on the reading sections of the Peabody Individual Achievement Test.

Because of the wide discrepancy between the reading ability of the citizenship and the readability levels of the health education materials, writers recommend lowering the readability grade level of materials to less than grade 9 (Spadero, 1983), 8-9 (Lange, 1988), 8 or less (LaPierre \& Mallet, 1987), less that 8 (Farell-Miller \& Gentry, 1989), 7 (Davis et al., 1990), or 6.5-8.5 (Matthews, Thornton \& McLean, 1985). It is assumed that lowering the readability level of the text will increase comprehension by the readers.

A decade ago, advice emphasized relying heavily on readability formulas. For example, Vivian and Robertson (1980) wrote: "Producers of patient education materials should apply readability formulas to ascertain the comprehensibility of the offered material" (p. 135). Vivian and Robertson advise shorter words and sentences for increased comprehension.

But because readability formulas usually rely on estimates of only two variables-word difficulty and sentence difficulty-patient education experts now advise considering other variables affecting comprehension: the reader, content, organization, and format. 
They advise, for example, stimulating the reader's interest (Lange, 1988), defining semi-technical terms (Gibbs, Gibbs, \& Henrich, 1987), ensuring an introduction, body, and summary (Lohr, Ventura, Crosby, Burch, \& Todd, 1989), as well as making the changes necessary to lower the readability level as measured by the formulas. However, the literature does not address a key question: Is the relationship between simplification and comprehension incremental or all-or-nothing? Is it true that the more readability tips implemented in writing a text the more comprehensible the text becomes? Or must nearly all readability advice be followed to engender significantly improved comprehension? Nor does the literature seriously question the assumption that lowering the readability level of health education materials to about the grade 7 level as measured by readability formulas will increase comprehension significantly.

\section{Readability and Formulas}

While the literature on health education now recommends more than simplifying vocabulary and shortening sentences, the readability formula score is still the imprimatur. This may place unwarranted confidence in readability formulas. A readability formula is "a predictive device intended to provide quantitative, objective estimates of reading difficulty" (Klare, 1984, p. 684). All rely on estimates of word and sentence difficulty. The Flesch-Kincaid, for example, uses average sentence length and word length, as the following simplified version of the formula shows:

Grade Level $=.4$ (words/sentence) +12 (syllables/word) -16 (Klare, 1984, p. 693).

Klare reminds us that such formulas are designed to predict readability, not to produce it. In developing readability formulas, researchers establish a correlation between reader comprehension (usually measured by cloze tests) of different passages and some elements of the passages. Estimates of word and sentence difficulty in passages give the highest convenient and reliable correlation with comprehension. This research does not claim that the relationship is causal. It is worth noting that while such formulas predict readability, they do not measure readability. While formulas or expertise applied to a text yield predictions of readability, tests of reader comprehension measure readability.

Of the most common readability formulas, the Flesch seems well suited to our research. The Spache formula is designed for very elementary materials (grades 1-3). The Dale-Chall is based on a 
dated list of common words (Dale \& Chall, 1948). The Raygor yields essentially the same results as the Fry, counting letters in words rather than syllables (Baldwin \& Kaufman, in Klare, 1984). Although the raw scores from the Fry, Flesch, and SMOG formulas correlate highly, when these scores are converted to grade equivalents, SMOG yields grade levels higher than other formulas (Spadero, 1983) and Fry yields scores lower than average (Guidry \& Knight, 1976). According to Klare, author of the readability chapter in Handbook of Reading Research (1984), the Flesch is the most widely used, and "more computer programs have been developed to apply [it] than any other formula" (p. 690).

Even used properly, readability formulas have many weaknesses. Formulas have high correlations with passage difficulty when they are tested with a wide range of readers on a large number of texts of varying content and difficulty. But in normal application, formulas are often used for a narrow range of reading ability and a small number of passages on a particular subject and with a restricted range of difficulty. This use is legitimate, but the predictive power of the formulas decreases. It is also well to remember that the predictive power of formulas was generally developed with school pupils and the extrapolation to adults, speakers of English as a second language, and especially ESL adults must be viewed critically.

Yet readability formulas will continue to be used widely because alternatives are not promising. Testing-that is, actually measuring readability-is time consuming, requiring creating valid and reliable tests, administering them to appropriate subjects under suitable conditions, and calculating and interpreting results. Judging, a common method, is risky for non-experts. Even people who are usually considered to be good judges of readability may not be. Klare (1984) cites research showing school and public librarians rating one book from grade 3 to grade 12 in difficulty, professional writers rating five passages at all but one of the five possible levels of difficulty, and teachers' judgements varying by six to nine grade levels. Individuals who are not specially trained are not reliable judges of readability.

\section{Readability and ESL}

Although readability formulas are less commonly used in the ESL field than the health education field, readability in ESL often has a similar focus: vocabulary size and the difficulty of grammatical structures (Hetherington, 1985). Numerous authorities argue 
eloquently for including considerion of content, discourse features, format, and, most importantly, the reader, as well as linguistic variables (Carrell, 1987; Hetherington, 1985; LotheringtonWoloszyn, 1988). The research is sparse and inconclusive, but it calls into question focusing heavily on the lexical and syntactical.

Johnson's (1981) study indicated by multivariate analysis of variance that "the level of syntactic and semantic complexity [of an English language text] had a lesser effect than did the cultural origin of the text on the reading comprehension" (p. 171) of 46 Iranian intermediate/advanced ESL students at an American university. Nonetheless, the Iranian students understood the simplified version of an American folk story better than the unaltered original.

Blau (1982) developed three versions of 18 paragraphs, each version differing in the degree of sentence combining. Analysis of covariance indicated no significant difference in comprehension for 85 Puerto Rican ESL college students among version 1 (primarily simple sentences), version 2 (complex sentences with surface clues to relationships), and version 3 (complex sentences with sophisticated, subtle clues to relationships). Post hoc, says Blau, one could reason as follows: If one were to use readability levels as a guide in formulating a directional research hypothesis, a logical statement would be that comprehension of version 1 will be superior to comprehension of version 2 , a one-tailed t-test. This hypothesis would not be supported $(p<0.45)$.

Floyd and Carrell (1987) were able to achieve more definite results by making the variables extreme. Twenty intermediate-level ESL students were divided into an experimental group which experienced two carefully planned, dynamic lessons on Independence Day in Boston, and a control group which did its normal school work. Both groups read a letter about the Fourth of July celebrations in Boston, half the students reading an unaltered text (average $\mathrm{T}$-unit length $=11.34$ ) and half reading a syntactically less complex text (average T-unit 8.67 words). As measured by an objective test and a free written recall test, teaching the cultural background facilitated reading comprehension, but differences in syntactical complexity showed no significant difference in comprehension.

Brown (1985) tested intermediate ESL students (mean reading grade level $=5.6$ ) on three versions of a text: (1) the original version (grade 10 level); (2) a modified input version where sentence structure and vocabulary were simplified (grade 5 level); and a modified interaction version where repetition, definition, and clarification were used in an effort to enhance comprehension 
(grade 9 level). The 30 ESL students scored as follows on the 20question multiple-choice test: (1) 8.6 correct, (2) 14.3 , and (3) 13.5 . Although the differences are not statistically significant, they suggest the power of modified interaction to help ESL students comprehend material which formulas predict is too difficult.

Strother and Ulijn (1987) altered 10 sentences in a general article about computers. They syntactically simplified three structures frequent in the science and technology register: passives, nominalizations, and participles. They gave the two versions of the article to three groups: $\mathrm{L}_{1}$ computer and humanities students, ESL Dutch and Chinese computer students, and a variety of ESL students not enrolled in computer courses. Participants answered 10 true/false questions directly related to the 10 altered sentences. Strother and Ulijn found "no significant differences among various groups, whether controlling for language background, background knowledge of the subject to be tested, or the register of the text itself" (p. 97). Although this study has several significant flaws, it is useful in pointing out the difficulty of detecting comprehension differences when only minor grammatical changes are made to a text.

These studies cast doubt on the significance of lexical and syntactical simplification, and they show the difficulty of detecting change when only minor variables are manipulated. Klare (1984) has identified 156 distinct readability variables. Rather than trying to test them one at a time, it may be advisable to test several at once. We made several kinds of textual changes in "simplifying" the health education material used in testing the following null hypothesis: There is no difference in comprehension between adult ESL students who read a "simplified" version of a general pharmacy education pamphlet and those who read a more difficult version.

\section{METHOD}

\section{Design}

This experimental study was a posttest-only control group design. Students at the advanced level and students at the low-intermediate level were randomly assigned at each level to groups, one receiving version A (unaltered) of the pamphlet (24 subjects), the other version $B$ (altered) of the pamphlet ( 25 subjects). After reading the pamphlets, all students wrote the same comprehension tests. 


\section{Pamphlets and Tests}

Version A of the pamphlet was written by a hospital clinical pharmacist as general information on how to take medication safely and effectively. The readability level was grade 12 as calculated by the Flesch-Kincaid as incorporated in the computer software Grammatik $I V$.

In revising version A, we did not "write to formula," making only those word and sentence length changes which would lower the readability score. We did not identify and eliminate three-syllable words. We did not analyze complex sentences and then turn them into simple sentences. Rather, as health professionals might do, and as many plain language consultants do, we aimed to write natural, considerate prose rather than calculated, simple prose. But then, as health professionals would do, we checked the readability level. After four revision cycles, we obtained a readability score of grade 7 and, as recommended in the health education literature, stopped revising. For the types of changes made and not made, see Table 1. For excerpts from versions A and B, see Appendix A. The content in versions $A$ and $B$ was judged to be essentially the same by four hospital pharmacist, two with more than 15 years' experience and two with 3 years' experience. The teachers of the low-intermediate classes judged version $B$ as understandable by their classes, and the teachers of the advanced classes judged version A comprehensible to their students.

\section{TABLE 1}

Types of Changes Made and Not Made to Version A

Changes made

Sentences

a) shortened

b) simplified structure, especially active instead of passive construction, and fewer subordinate clauses

c) made less abstract (e.g., direct form of address: "you")

\section{Vocabulany}

a) used fewer lengthy words

b) used fewer technical words

c) used fewer difficult words

d) defined key terms 


\section{Introduction}

a) provided a more interesting, concrete title

b) caught attention with the opening sentence

c) gave a specific purpose or purposes for reading

\section{Organization}

a) organized points by chronology and importance

b) organized individual points to emphasize main ideas through topic sentences placed first

\section{Format}

provided short, bold imperatives for each point

\section{Some changes not made}



a) spacing not changed

b) not all upper and lower case letters

c) type not large (e.g., 12 or 14 point)

d) graphics not added

Discourse genre or type

not changed from a list

In light of what the patient education pamphlet tried to achieve, two reading comprehension tests were constructed. Pharmacists want patients going home to remember the content of the pamphlet and then use what they have learned about taking their medication safely. To approximate the emphasis on remembering, we gave participants a free written test asking them to list 10 of the 12 points in the pamphlet. But patients' home environments may help them recall advice they have forgotten. For example, going to take medicine in the dark may remind them of the prohibition against doing so. Thus we gave participants a short-answer test which asked them to fill in the blanks on times requiring recall of details and on 
items requiring application of information from the pamphlet. See Appendix B for excerpts from the tests.

\section{Subjects}

The 49 subjects were adult students in an academic preparation ESL program at a Canadian community college. The advanced level was the last of seven levels before mainstream college courses. Both advanced classes volunteered for the study. The low-intermediate level was the third of the seven levels. Two of the three classes volunteered. The instructor of the third class refused to participate because she felt that she could not afford to relinquish the two class periods required for the study. Twelve of the potential 61 subjects did not complete the study: 10 were absent from the first or second session, 1 refused to finish the tests, and 1 moved to a class not involved in the study.

As a demographic questionnaire showed, the subjects were a varied group. They spoke a wide variety of first languages, with only Spanish (13 subjects) and Cantonese (11) forming noticeable groups. Ages ranged from 18 to 48 , the mean being 24 . Evaluation of the demographic data using boxplots and exploratory data analysis showed no important differences between the group which read the altered pamphlet and the group which read the unaltered. Neither were CAAT reading scores significantly different (difference in means $=4.78 ; 95 \%$ confidence interval for difference in means $=$ $(-7.5,1.1) ; p=0.14)$. This indicates that randomization techniques were effective.

\section{Procedure}

We pilot tested procedures and tests with an intermediate-level ESL class at the college. This helped us clarify instructions, revise test questions, and determine a maximum reading time of eight minutes.

One researcher (JB) conducted all of the classroom sessions in an effort to ensure consistency and to provide a check that the subjects were taking the tasks seriously. First, all subjects were tested with the reading comprehension section of the appropriate level of the Canadian Adult Achievement Test (CAAT). This test is up-to-date, designed for adults, and emphasizes functional reading skills. All students completed a questionnaire designed to collect demographic information. Subsequently, students were given their CAAT results and reading profiles, and told how to interpret the results. 
In the second session, students read version $\mathrm{A}$ or $\mathrm{B}$ of the pamphlet and answered questions on what they had read. To increase motivation, students were told that during the session they would learn important knowledge about taking medication safely and effectively, that they would help a hospital design a pamphlet suitable for its many ESL clients, and that they would be taught a memory technique to improve reading comprehension. Students were then instructed to read the pamphlet at their average reading speed and to try to remember the contents. They were asked not to study or attempt to memorize it. When finished, the students noted the time taken, according to times written on a blackboard at 30 second intervals.

Subjects then completed a freely written recall test (Part I) which asked them to list 10 or the 12 points in the pamphlet. After handing these in, they were given 15 fill-in-the-blank questions (Part II). To finish the session, students were taught a short lesson on remembering lists by associating list items with images.

The Tests were marked independently by the researchers. On any test where scores differed by more than one point, the difference was resolved through discussion. Part I and Part II scores were averaged separately.

Data were analyzed using the Minitab statistical package for IBM computers. Demographic data were compared using the KruskalWallis test for ranked data. Chi-square tests and exploratory data analysis were used for categorical data. Mean CAAT scores, time, and comprehension test scores were analyzed using Student's t-test. The a priori level of significance was set at 0.05 .

\section{Results}

We found no statistically significant differences between the comprehension test scores of the group reading the unaltered version and the group reading the altered version of the pamphlet (See Table 2). There was no statistically significant difference between the groups' scores on the free written test or on the short answer test. Subjects finished the unaltered pamphlet in a mean time of 5.12 minutes, the altered version in 5.34 minutes. The difference in reading time was not statistically significant [mean difference $=0.22 ; \mathrm{CI}=(-0.66,1.09) ; p=0.62]$. 
TABLE 2

Results of Comprehension Tests

\begin{tabular}{lcccc}
\hline \hline & Mean & $\begin{array}{c}\text { Mean } \\
\text { Difference }\end{array}$ & $\begin{array}{c}\text { Confidence } \\
\text { Interval }\end{array}$ & $\begin{array}{c}p \\
\text { Value }\end{array}$ \\
\hline Tests & & & & \\
\hline $\begin{array}{l}\text { Part I } \\
\text { Unaltered text group }\end{array}$ & 6.03 & 0.04 & -0.94, & 0.80 \\
& & & 1.22 & \\
Altered text group & 6.17 & & & \\
Part II & & & & \\
Unaltered text group & 11.30 & 0.52 & -2.48, & 0.59 \\
Altered text group & 10.77 & & 1.42 & \\
& & & & \\
\hline
\end{tabular}

Because of low-intermediate students who were particularly good readers and advanced students who were unusually weak readers, the combined comprehension test scores (Part I + Part II) ranged fairly evenly from 9 to 26 out of a possible 29 correct. This range, however, raises an important consideration: perhaps no significant difference was detected between the groups reading version $A$ and $B$ because the advanced readers, who could comprehend both difficult and easy versions, washed out a significant difference between lowintermediate students who read version $A$ and those who read version $B$. To investigate this possibility, we looked at the two levels separately. Although the size of each group becomes too small to allow conclusions with confidence, there seems to be no significant difference between advanced students' comprehension of versions $A$ and $B$ (as might be expected), but neither does there seem to be a significant difference among low-intermediate students' comprehension of versions A and B (See Table 3). These smaller groups did not differ significantly on demographics, reading scores or pamphlet reading time. 


\section{TABLE 3}

\section{Results of Comprehension Tests by Level}

\begin{tabular}{lcccc}
\hline & Mean & $\begin{array}{c}\text { Mean } \\
\text { Difference }\end{array}$ & $\begin{array}{c}\text { Confidence } \\
\text { Interval }\end{array}$ & $\begin{array}{c}p \\
\text { Value }\end{array}$ \\
\hline \multicolumn{5}{c}{ Low-Intermediate Level } \\
Part I (total score=10) & & & \\
Group A (Unaltered) & 5.35 & 0.54 & -1.86, & 0.40 \\
& & & 0.78 & \\
Group B (Altered) & 4.81 & & & \\
Part II (total score=19) & & & -3.86, & 0.28 \\
Group A (Unaltered) & 9.70 & 0.79 & 1.21 & \\
Group B (Altered) & 8.37 & & &
\end{tabular}

Advanced Level

$\begin{array}{ccccc}\begin{array}{c}\text { Part I (total score=10) } \\ \text { Group A (Unaltered) }\end{array} & 6.89 & 0.13 & -1.50, & 0.86 \\ & & & 1.56 & \\ & & & & \\ \text { Group B (Altered) } & 7.02 & & & \\ & & & & \\ \text { Part II (total score=19) } & & 0.02 & -2.33, & 0.98 \\ \text { Group A Unaltered) } & 12.71 & & 2.28 & \end{array}$

Group B (Altered) $\quad 12.69$

\section{Discussion}

Why did lowering the readability level of the health education materials from grade 12 to grade 7 levels make no significant difference in comprehension for the ESL readers?

Although it is possible that the sample size of 49 was too small to detect a difference, the mean scores of the experimental and control groups were so close that it is doubtful that a larger sample size would have revealed a significant difference.

The motivation of the students to remember the information contained in the pamphlet might also be questioned. However, only 
one of the students refused to complete the task, and the person administering the tests noted that the students seemed to take the task seriously. It is tempting to compare the students' motivation in reading general interest health education material with the patients' motivation, and to see the patient as highly motivated because he or she has been prescribed medication. However, the patient may not read the information at all. Or the patient might be so anxious that comprehension is hindered. Therefore, the difference in motivation between patients and keen academic students may not be as great as might be assumed.

Besides motivation, background knowledge is probably the major variable in comprehension (Klare, 1984). Thus cultural background may have made comprehension difficult. The only way in which the study addressed this was to have subjects from a wide variety of cultures.

A major factor affecting comprehension was the difficulty of remembering a list of 10 points. This is especially true because subjects were instructed to read, not study, the pamphlet. Furthermore, the items are not clearly inter-related, so remembering one item does not necessarily bring to mind another item. Although the items were re-arranged into a somewhat chronological order in version $B$, this may have been too subtle for students to detect and to use as a memory aid.

Perhaps the grade 7 reading level of the altered pamphlet was not easy enough for low-intermediate readers. Although both lowintermediate instructors thought their students could comprehend the pamphlet, one teacher pointed out elements which students might find difficult. Some vocabulary was fairly advanced: swallowing, procedure, label, effect, transfer, original, harmful, and guide. Speakers of Romance languages, such as the 13 Spanish speakers in this study, might use their knowledge of Latin-based words to understand procedure, effect, transfer, and original; but subjects such as the 11 Cantonese speakers would have no such help. However, all of the above words identified as difficult were defined by their context. In addition to vocabulary, some sentences and expressions were fairly difficult for low-intermediate students. Consider this sentence from the point encouraging readers to ask their pharmacist for additional information about their medication: "This information and advice from your pharmacist is part of the cost of your medication." Although this is a simple sentence with vocabulary the readers know, it is rather abstract. "Your pharmacist will give you this information free" is not quite accurate factually, but it more concrete and easier to understand and remember. 
There may not have been enough difference between the two versions of the pamphlet. We made three substantial changes beyond lexical and syntactical: we included an introduction designed to stimulate interest and guide reading; we reorganized individual points and highlighted the topic sentence of each; and we reorganized the order of the points. But we did not make some of the other commonly recommended changes. We did not add graphics and enlarge the type and leave more white space for an inviting design, easy on the eye. We did not make the organization explicit, say, by using large headings. Nor did we simplify the vocabulary and sentence structure as much as we might have. And the lengthy, twelve-point list remained intact. Consequently, the pamphlets may not have been altered enough to produce a significant difference in comprehension.

To assume that lowering the readability level-even as much as five grade levels-results in improved comprehension for adult ESL readers is risky. That assumption is suspect even when some changes beyond the lexical and syntactical are made. This suggests making nearly all of the commonly recommended readability changes when simplifying a text. The assumption is that so radically altering a document will result in improved comprehension, but, of course, this should be tested.

\section{ACKNOWLEDGEMENTS}

1. This study was supported by a grant from the Research and Development Committee, Calgary General Hospital.

2. We gratefully acknowledge the help of D. George, D. Goring, J. Goring, P. Pankratz, R. Raughton, A. Trussler, D. Van Staalduine, D. Warkentin, D. Wood, H. Holley for her assistance with the statistical analysis, and the Department of Psychiatry, Calgary General Hospital, for access to computers and statistical software.

\section{THE AUTHORS}

James Bell (Ph.D., University of Texas) is director of the Calgary Adult Literacy Awareness Project. He is particularly interested in teaching written composition.

Reta Johnson (Pharm.D., University of Texas) is Manager, Clinical, Research and Education at The Calgary General Hospital. She is particularly interested in pharmacy care plans. 


\section{REFERENCES}

Blau, E. K. (1982). The effect of syntax on readability for ESL students in Puerto Rico. TESOL Quarterly, 16(4), 517-527.

Brown, R. L. (1985). A comparison of the comprehensibility of modified and unmodified ESL reading materials. Unpublished master's thesis, University of Hawaii, Honolulu, HI.

Carrell, P. L. (1987). Readability in ESL. Reading in a Foreign Language, 4(1), 21-40.

Dale, E. \& Chall, J. S. (1948). A formula for predicting readability. Educational Research Bulletin, 27, 11-20, 37-54.

Davis, T. C., Crouch, M. A., Wills, G., Miller, S., \& Abdehou, D. M. (1990). The gap between patient reading comprehension and the readability of patient eduction materials. The Journal of Family Practice, 31(5), 533-538.

Doak, C. C., Doak, L. G., \& Root, J. H. (1985). Teaching patients with low literacy skills. New York: J. B. Lippincott.

Farrell-Miller, P. \& Gentry, P. (1989). How effective are your patient education materials? Guidelines for developing and evaluating written educational materials. The Diabetes Educator, 15(5), 418-422.

Floyd, P. \& Carrell, P. L. (1987). Effects on ESL reading of teaching cultural content schemata. Language Learning, 37(1), 89-108.

Gibbs, R. D., Gibbs, P. H. \& Henrich, J. (1987). Patient understanding of commonly used medical vocabulary. The Journal of Family Practice, 25(2), 176-178.

Guidry, L. J. \& Knight, D. F. (1976). Comparative readability: Four formulas and Newberry books. Journal of Reading, 19, 552556.

Hetherington, A. (1985). Assessing the suitability of reading materials for ESL students. TESL Canada Journal, 3(1), 37-51.

Johnson, P. (1981). Effects on reading comprehension of language complexity and cultural background of a text. TESOL Quarterly, 15(2), 169-181.

Klare, G. R. (1984). Readability. In P. D. Pearson (Ed.), Handbook of reading research, (pp. 681-744). New York: Longman.

Lange, J. W. (1988). Developing printed materials for patient education. Dimensions of Critical Care Nursing, 8(4), 250-258.

Lohr, G., Ventura, M. R., Crosby, F. , Burch, K., \& Todd, K. (1989). An experience in designing patient education materials. Journal of Nursing Staff Development, 5(5), 218-224. 
LaPierre, G. \& Mallet, L. (1987). Readability of materials. Canadian Pharmaceutical Journal, 120, 718-728.

Lotherington-Woloszyn, H. (1988). On simplified and simplifying materials for ESL reading. TESL Talk, 18(1), 112-122.

Matthews, P. J., Thornton, L., \& McLean, L. (1985, July). The use of readability formulas in patient education materials. Paper presented at the American Association for Respiratory Therapy Summer Forum, Reno, NV.

Spadero, D. C. (1983). Assessing readability of patient information materials. Pediatric Nursing, 9, 274-278.

Strother, J. B. \& Ulijn, J. M. (1987). Does syntactic rewriting affect English for science and technology (EST) text comprehension? In J. Devine, P. L. Carrell \& D. E. Eskey (Eds.), Research in reading in English as a second language (pp. 89-110). Alexandria, VA: Teachers of English to Speakers of Other Languages.

Vivian, A. S. \& Robertson, E. J. (1980). Readability of patient education materials. Clinical Therapeutics, 3(2), 129-136. 


\section{APPENDIX A}

\section{Sample Points from the Health Education Pamphlets}

Version A: Medication guide for the home patient

1. When your physician prescribes medication for you, be sure to take it. Is is a waste of time and money if you visit your doctor for advice and then do not follow it.

2. It is essential to follow the instruction for taking your medication. The dosage time interval between doses, and the duration of your prescription therapy were carefully specified by your physician and are all essential to the success of your treatment. Follow the instructions exactly, for too low a dosage can be just as dangerous as taking too much.

3. In order to avoid taking the wrong medication, follow a practice used by pharmacists to avoid mistakes...read the label three times: once, before you remove the medicine from the cabinet; again, before you take it; and a third time, when you return it to the medicine chest. Never take medicine in the dark, no matter how sure you think you are of its location. Keep the label up when pouring liquid medication, so that the instructions do not become obscured by drippage.

Version B: Medication Guide: How to take your medication properly

1. TAKE YOUR MEDICATION. Your doctor chose the best medicine for you. You waste time and money if you do not follow your doctor's advice.

2. FOLLOW THE INSTRUCTIONS FOR TAKING YOUR MEDICATION. Your doctor carefully chose how much medication you should take. Your doctor also carefully decided when you should take it. Your medication will work better if you follow the instructions exactly. Too much medication or too little medication can be harmful.

3. READ THE LABEL. On the label, your pharmacist prints instructions about how you should take your medication. Then the pharmacist puts this label on your medication container. Make sure you understand these instructions. Each time you take your medication, you should read the label to make sure you have the correct medication. Do not take your medication in the dark because you might take the wrong one. Keep the label facing you when you pour liquid medication so that it does not run down the label and make the instructions hard to read. 


\section{APPENDIX B}

\section{Excerpts from Comprehension Tests}

\section{Part I: Question on Medication Guide" [Free Written Test]}

INSTRUCTIONS: The medication guide gave you 12 helpful hints or instructions for taking medication correctly and safely. Write as many of these rules as you can remember. Please write sentences. You may write the rules in any order. The first and last rules are provided for you.

1. Take your medication.

2.

3.

Part II: Questions on "Medication Guide" [Short Answer Test]

INSTRUCTIONS: Please fill in the blanks with information from the pamphlet "Medication Guide".

6. If you feel better before you finish taking all of your medication you should

12. You have been working in your yard all weekend, and now your back is sore. You talk to your brother-in-law. He tells you that he had the same problem 2 weeks ago, and his doctor ordered some medication that really worked! He offers it to you, since his own back is better now. You should 